\title{
The Value of Originality and Proper Quotation
}

\author{
Jeong Tae Kim, MD, PhD \\ Editor-in-Chief, Archives of Plastic Surgery
}

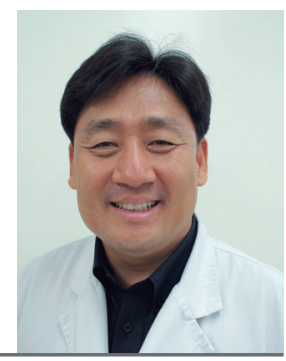

For a journal article of quality, an excellent concept and significant results are basic requirements. However, a more important factor is how to make a coherent argument. To explain the article's subject, scientific and logical discourse is necessary. In addition, appropriate quotations are needed to support the key claims because quotations situate the claims of the article within a community of scholars and a history of scholarship. However, if some parts of the text, photographs, and tables are used without the original authors' permission in ignorance of standard citation practices, the outcome could be plagiarism, which is considered a serious offence in the international scientific community. Recently, about 50 new English medical journals have been launched in Korea. In addition, more and more local journals have been listed in database indices such as SCI, Scopus, and PubMed. Through this process, plagiarism, which is a signal of an immature publication, should be eradicated.

According to the Office of Research Integrity which is a U.S. Department of Health and Human Services-affiliated organization, 26 guidelines for "A guide to ethical writing" are proposed on their website (http://ori.hhs.gov) to avoid plagiarism [1]. These guidelines include the following: references should be identified, and original words, phrases, and clauses should be enclosed in quotation marks. In addition, only necessary and valuable content should be quoted in the original authors' exact words. Primary literature, which is the content of original papers, should be quoted rather than citing the summary of work in secondary sources. Quotations can be classified into three types: verbatim, paraphrasing, and summary. Verbatim means to quote some exact words of the original sentences. Paraphrasing is to change some words while conveying the original concept. Summary is to describe an author's key ideas, generally more briefly than in the original. Verbatim quotations require quotation marks and a citation Paraphrase and Summary should present in original authors' original intent and also require a citation [1]. Although these ethical principles have been publicized in the scientific community, the number of suspected duplicates in the biomedical literature has increased every year [2]. The primary reason is that authors overlook plagiarism when citing other papers. Another reason is that it is difficult to find plagiarism even when examiners evaluate papers carefully.

Academic publishers have tried to develop software to check the similarity of new submissions with existing articles, in order to fight plagiarism. At the beginning of the first decade of the 21st century, eTBLAST, which was a text similarity-based search engine was developed and a free text similarity service was provided by this engine [3]. However, it had the limitation that only abstracts were compared from the Medline database. CrossRef, which includes more than 3,700 publishers and societies and content items with more than 50,000,000 digital object identifiers for digital items such as journals and conference proceedings, had been concerned about plagiarism since 2006. CrossRef collaborated with iParadigms to launch the CrossCheck service named iThenticate to check for similarity in June 2008 [4]. CrossCheck reports the similarity of a whole article with existing items by searching a massive database and matching passages with CrossRef in a few tens of seconds. Similarity is presented as a percentage. Lists of similar articles and details of the similar parts of the texts are shown. In other words, passages which have high similarity are presented in different colors according

Copyright (C) 2012 The Korean Society of Plastic and Reconstructive Surgeons

This is an Open Access article distributed under the terms of the Creative Commons Attribution Non-Commercial License (http://creativecommons.org/

licenses/by-nc/3.0/) which permits unrestricted non-commercial use, distribution, and reproduction in any medium, provided the original work is properly cited.

www.e-aps.org 
to which paper they seem to quote. In addition, suspected duplicates are easily found by linking to the search for quoted papers. Many file types can be uploaded, including Word, Word XML, Text, PostScript, PDF, HTML, WordPerfect WPD, and RTF, so that various types of documents are compared in CrossCheck. However, the limitation of CrossCheck is that photographs, charts, tables, and equations in requested manuscripts cannot yet be compared. The permission for quotation of photographs and tables should be obtained through the normal process according to the author's conscience. References should be identified below quoted photographs and tables.

CrossCheck is being used in 47 out of 206 Korean Association of Medical Journal Editors journals. Archives of Plastic Surgery (APS) is one of them. The similarity of submitted articles for APS is verified by CrossCheck. The results are attached to the content sent to the reviewers for the review process. The similarity among 87 articles that were submitted to APS from January to May 2012 was $17.5 \%$ by CrossCheck, and among them, 3 articles were rejected because of a high similarity of more than $50 \%$. CrossCheck is not a perfect method for checking plagiarism because it is not easy to identify plagiarism by only sentence similarity. Even more problematic than words quoted without proper citation is ideas and results from another author presented without proper citation. However, the latter cannot be checked by CrossCheck. Nevertheless, the reason CrossCheck is still performed is to identify articles that have been written by simply duplicating the contents of other articles verbatim. If the concept presented in an article is perfect, but parts have been copied from other articles, the article still is not qualified for publication. In addition, such an article could be considered plagiarism. Analyzing articles found to have high similarity by CrossCheck in the APS editorial office, it was found that many parts of these articles were duplicated from existing articles.

In addition, recently APS requested a retraction from another journal and asked other journals that plagiarized the photographs of APS to make a greater effort to prevent plagiarism. Some papers which were suspected duplicates were rejected from publication through the review process. Articles fit for publication can be written when the author recognizes that the originality of report is as valuable as his own research content. These articles would make outstanding journal content, and many readers would be satisfied with the journals that maintain these standards. Authors should not be ashamed to quote support for their arguments from other articles and books. Identifying quoted sources appropriately is also a great service to the reader, who may wish to follow-up by reading the cited article. APS expects many articles worthy of publication will continue to be submitted, raising the profile of the journal in the plastic and reconstructive surgery field.

\section{REFERENCES}

1. Miguel R. Avoiding plagiarism, self-plagiarism, and other questionable writing practices: a guide to ethical writing [Internet]. Rockville: U.S. Department of Health and Human Services; c2012 [cited 2011 Sep 29]. Available from: http://ori.hhs.gov/avoiding-plagiarism-self-plagiarism-andother-questionable-writing-practices-guide-ethical-writing.

2. Errami M, Garner H. A tale of two citations. Nature 2008; 451:397-9.

3. eTBLAST: a text-similarity based search engine [Internet]. Blacksburg: Virginia Tech: c2011 [cited 2012 Jun 30]. Available from: http://etest.vbi.vt.edu/etblast3.

4. iThenticate. CrossCheck [Internet]. Oakland: iParadigms, LLC; c2012 [cited 2011 Jun 13]. Available from: http:// www.ithenticate.com.

Correspondence: Jeong Tae Kim

Department of Plastic and Reconstructive Surgery, Hanyang University Medical Center, 345 Wangsimni-gil, Sungdong-gu, Seoul 133-792, Korea

Tel: +82-2-2290-8560, Fax: +82-2-2295-7671, E-mail: jtkim360@gmail.com

No potential conflict of interest relevant to this article was reported.

Received: 30 Jun 2012 • Revised: 1 Jul 2012 • Accepted: 2 Jul 2012

pISSN: 2234-6163 • elSSN: 2234-6171

http://dx.doi.org/10.5999/aps.2012.39.4.279 • Arch Plast Surg 2012;39:279-280 